\title{
Effectiveness of orthoses for treatment in patients with spinal pain
}

\author{
Yoo Jin Choo, Min Cheol Chang \\ Department of Physical Medicine and Rehabilitation, Yeungnam University College of Medicine, Daegu, Korea
}

Received: March 11, 2020

Revised: March 16, 2020

Accepted: March 17, 2020

Corresponding author:

Min Cheol Chang

Department of Physical Medicine

and Rehabilitation, Yeungnam

University College of Medicine, 170

Hyeonchung-ro, Nam-gu, Daegu

42415, Korea

Tel: +82-53-620-4682

Fax: +82-53-625-3508

E-mail:wheel633@ynu.ac.kr
Spinal pain is a common patient complaint in clinical practice. Conservative treatment methods include oral medication, physical therapy, injections, and spinal orthoses. The clinical application of orthoses is debated because of potential complications associated with long-term use, such as muscle weakness and joint contracture. We reviewed the orthoses most frequently used to manage spinal pain. We review the use of soft cervical and Philadelphia collars, lumbosacral corsets, and thoracolumbosacral orthosis to manage spinal pain. Spinal orthoses can help reduce pain by protecting the muscles and joints of the injured spinal region, preventing or correcting malformations, and limiting trunk flexion, extension, lateral flexion, and rotation. The short-term use of spinal orthoses is known to improve pain and disability during the treatment period without significant adverse effects. Spinal orthoses are expected to alleviate pain and improve patients' lifestyle.

Keywords: Conservative treatment; Orthotic devices; Pain; Spine

\section{Introduction}

Spinal pain is a common patient complaint, affecting $80 \%-90 \%$ of individuals at least once in their lifetime [1,2]. There are various causes of spinal pain, such as spinal degeneration, trauma, inflammation, infection, and deformities. In clinical practice, spinal degeneration (herniated disc or spinal stenosis) and trauma are the most common causes of spinal pain [3-5]. To alleviate spinal pain, conservative treatments, including rest, physiotherapy (e.g., heat therapy, traction therapy, and manual therapy), injections, orthoses, and medication, are used before the surgical treatment [6-8]. Although the clinical application of orthoses is debated because of potential complications associated with long-term use, such as muscle weakness and joint contracture, its short-term use is known to improve pain and disability during the treatment period without significant adverse effects [9-11].
In this study, we reviewed the following types of orthoses most frequently used to manage spinal pain: soft cervical and Philadelphia collars, lumbosacral corset, and thoracolumbosacral orthosis (Table 1).

\section{Soft cervical collar}

The soft cervical collar is comprised of a soft foam material, a fabric covering the foam, and a Velcro strap (Fig. 1) $[12,13]$. The strap is mostly fastened at the back but can also be placed at the front, depending on the user's preference. Patients wearing a soft cervical collar can experience feelings of warmth and psychological comfort owing to the fabric sheathing [14]. However, soft cervical collars cannot significantly restrict the cervical spine's range of motion, thus falling short in providing sufficient structural support $[12,14]$. Therefore, they are used to manage muscle pain and 
Table 1. Characteristics of spinal orthoses

\begin{tabular}{|c|c|c|c|c|}
\hline & Soft cervical collar & Philadelphia collar & Lumbosacral corset & Thoracolumbosacral orthosis \\
\hline Material property & Flexible & Rigid & Flexible & Rigid \\
\hline Application part & Neck & $\begin{array}{l}\text { Chin, occiput, neck, upper por- } \\
\text { tion of trunk }\end{array}$ & $\begin{array}{l}\text { Abdomen, under the scapular, } \\
\text { upper supra-ilium }\end{array}$ & $\begin{array}{l}\text { Shoulder, thorax, abdomen, } \\
\text { medial part of scapula, dor- } \\
\text { sum, upper supra-ilium }\end{array}$ \\
\hline Movement limitation & Slight movement of $F, E, L-F, R$ & $F, E, L-F, R$ & $L-F$, slight movement of $F, E, R$ & $F, E, L-F, R$ \\
\hline Indication & $\begin{array}{l}\text { Spondylosis or minor trauma, } \\
\text { whiplash injuries }\end{array}$ & $\begin{array}{l}\text { Injuries of the bones or liga- } \\
\text { ments, post-operation }\end{array}$ & $\begin{array}{l}\text { Disc herniation, spinal stenosis, } \\
\text { chronic back pain, sprain }\end{array}$ & $\begin{array}{l}\text { Chronic back pain, sprain, } \\
\text { fracture, spinal deformities, } \\
\text { post-operation }\end{array}$ \\
\hline
\end{tabular}

$F$, flexion; $E$, extension; L-F, lateral flexion; $R$, rotation.

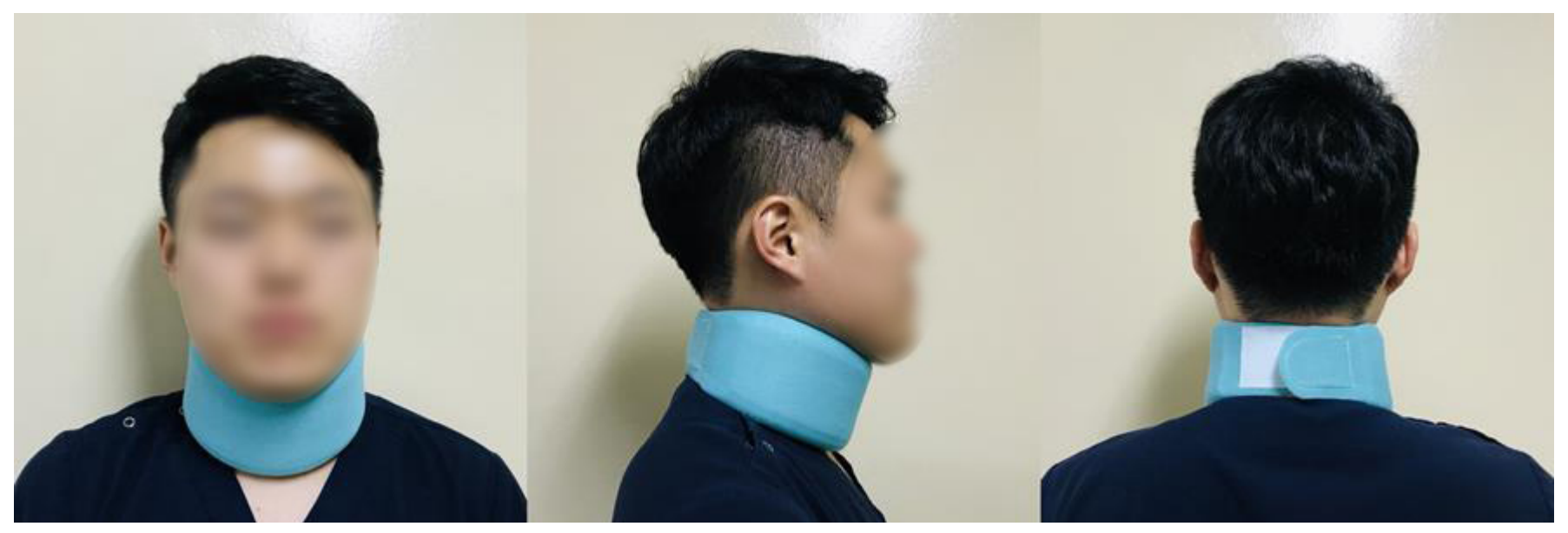

Fig. 1. Soft cervical collar. The subject is wearing soft cervical collar.

spasms due to spondylosis or minor trauma and as an initial treatment for whiplash injuries. According to a previous study, the soft cervical collar is recommended to be worn for 2 weeks [11].

Muzin et al. [11] reported no side effects (e.g., muscle weakness) associated with the use of soft cervical collars for fewer than 10 days. Mealy et al. [15] assessed 61 patients with acute cervical whiplash injuries following the use of the soft cervical collar for 2 weeks. The patients were divided into the following two groups: one that progressively combined exercise with use of the soft cervical collar and the other that performed exercise without use of the soft cervical collar. Eight weeks later, the visual analog scale (VAS) score from 0 to 10 (with 10 indicating unsustainable pain and 0 indicating absence of pain) and range of motion of the cervical spine (i.e., flexion, extension, lateral flexion, and rotation) were obtained. The group using the soft cervical collar reported a higher reduction in both the intensity of pain and range of motion of the cervical spine [15]. Furthermore, Rosenfeld et al. [16] investigated 97 patients with whiplash injuries by dividing them into two groups as follows: (1) those who wore soft cervical collars within 96 hours from the injury and were treated after 2 weeks and (2) those who did not use the collar and were treated using the same protocol. In addition, the VAS scores for pain were obtained for both the groups. After 6 months, the VAS scores decreased by 3 points in the group that used the soft cervical collars and only by 1.5 points in the group that did not use the soft cervical collar.

\section{Philadelphia collar}

The Philadelphia collar, which usually comprises of a solid plastic sheet, limits a greater range of movements compared to the soft cervical collar (Fig. 2) [12]. It is vertically reinforced from the chin to the manubrium in the front and shaped to cover the area from the external protuberance of the occipital bone to the upper part of the spine of the scapula at the back. The anterior part of the Philadelphia collar has a hole for tracheostomy; therefore, the user's chin has to be aligned with its center $[17,18]$. Furthermore, the inner side of the Philadelphia collar is lined with a replaceable padding, which permits good hygiene and causes less irritation to the skin. The Philadelphia collar slightly reduces the load on the spine by promoting the correct posture at the cervical spine and plays a role in limiting the cervical flexion/extension, lateral flex- 


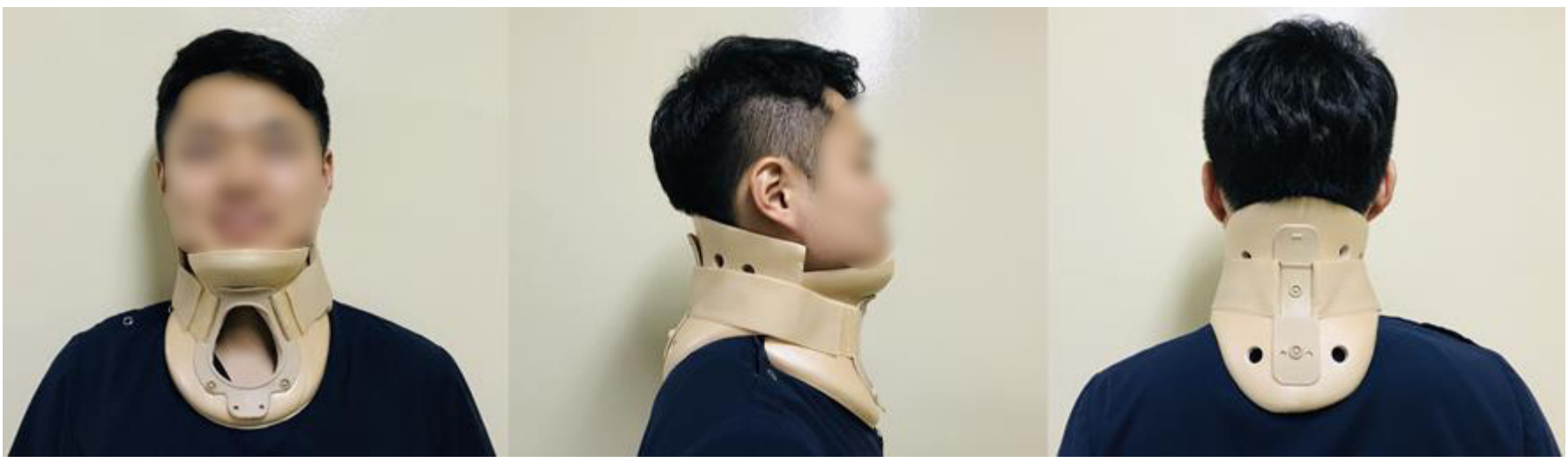

Fig. 2. Philadelphia collar. The subject is wearing Philadelphia collar.

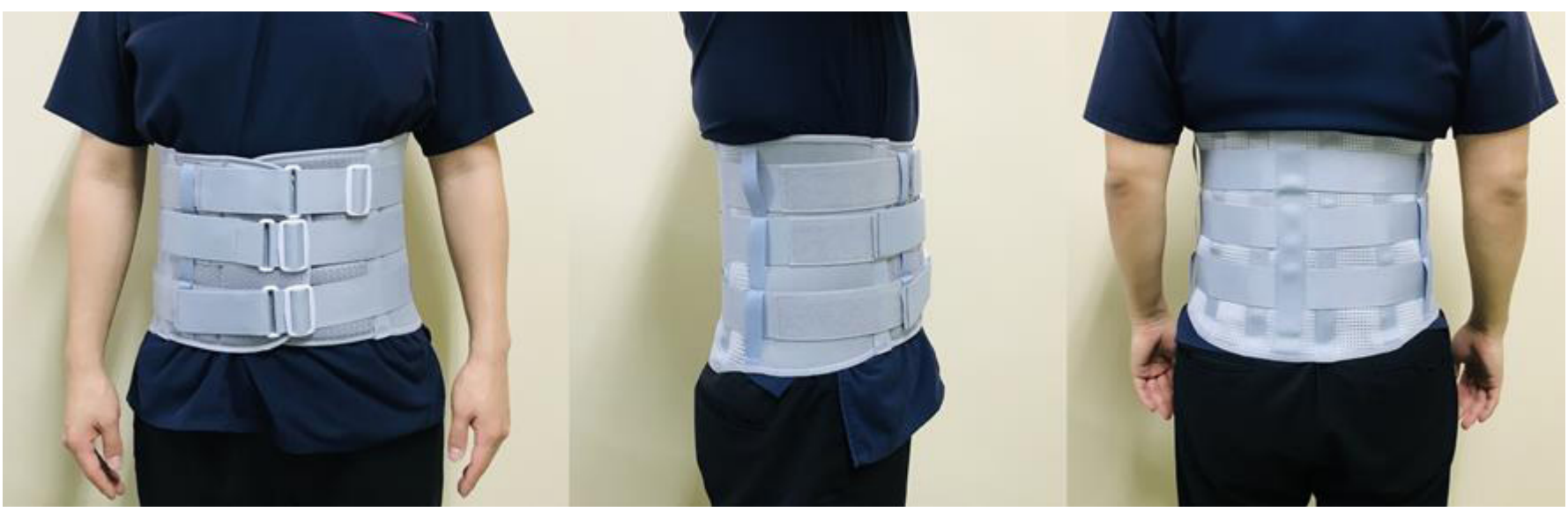

Fig. 3. Lumbosacral corset. The subject is wearing lumbosacral corset.
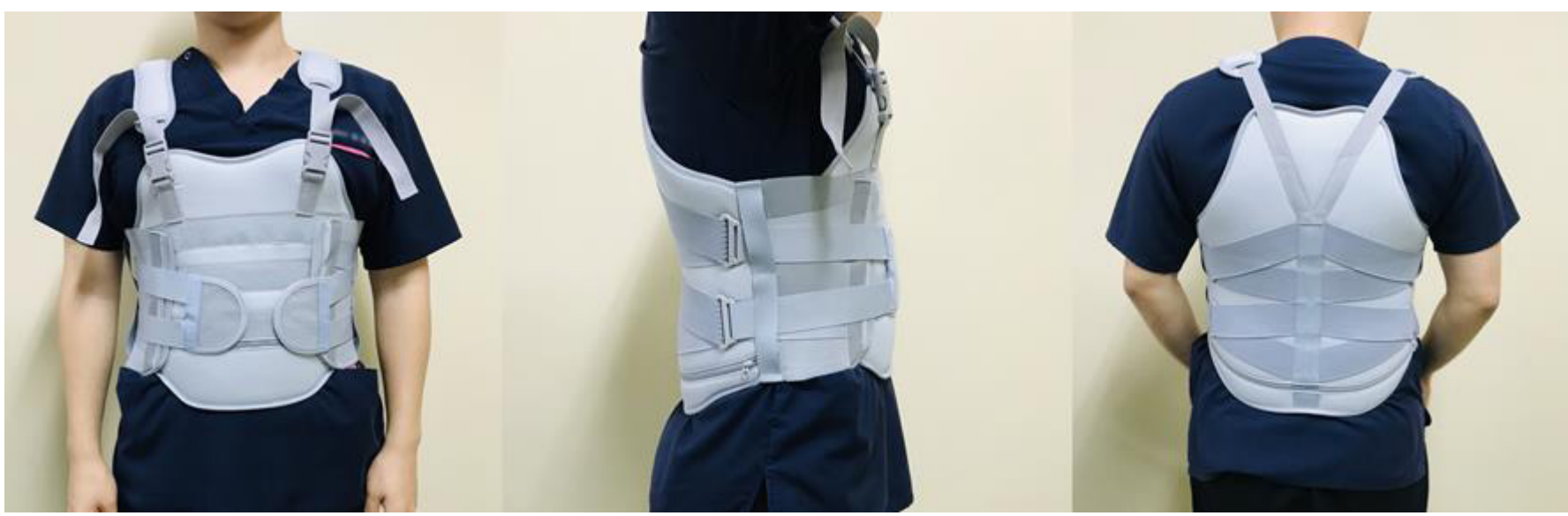

Fig. 4. Thoracolumbosacral orthosis. The subject is wearing thoracolumbosacral orthosis.

ions and rotation $[18,19]$. Nonetheless, some pressure may be applied on the clavicle by the Philadelphia collar. Considering that excessive pressure can cause discomfort or pressure sores, special attention is required for users with sensitive skin $[18,20]$. The
Philadelphia collar can be used to treat injuries of the bones and ligaments in the mid-cervical spine region and for postsurgical stabilization. In addition, it can be used instead of the halo orthosis to stabilize upper cervical fractures (Jefferson and hangman's 
fractures) and fractures of the odontoid process [11].

According to a study by Beavis [14], hard cervical collars are effective in limiting the motion of the cervical spine (level of movement reduction: flexion $69 \%$, extension $34 \%$, left lateral flexion $22 \%$, right lateral flexion $34 \%$, leftward rotation $50 \%$, and rightward rotation 48\%). Similarly, Muzin et al. [11] suggested that hard cervical collars were effective for the initial management of trauma (i.e., to prevent cervical instability). Finally, Motiei-Langroudi and Sadeghian [21] studied 11 patients with a C2 fracture who used the Philadelphia collar either until the bone completely recovered or until the neck pain disappeared. After a follow-up of 21 months, the patients reported no neurological symptoms or deficits, a mean VAS score of 2, and recovery of their lifestyle before the injury.

\section{Lumbosacral corset}

The lumbosacral corset is comprised of soft materials. It encloses the trunk and pelvis and has a string or hook to adjust the circumference. When necessary, a canvas, nylon mesh, or coil spring is used to increase its capability to provide support (Fig. 3). The posterior support column is made of semirigid or soft plastic materials and is molded to the shape of the patient's body. It is inserted into a corset, which confers rigidity to the support, thus limiting hyperextension of the spine and reducing spinal lordosis [2225]. In the groin region, straps can be attached to prevent the movement of the corset. The upper margin of the anterior surface of the corset is positioned $1.3 \mathrm{~cm}(1 / 2 \mathrm{inch})$ below the xiphoid process, and the lower margin is located $2.5-3 \mathrm{~cm}$ (1 inch) above the pubic symphysis. Furthermore, while the upper margin of the posterior surface is $2.5 \mathrm{~cm}$ ( 1 inch) below the inferior angle of the scapula, the lower margin is located at the most prominent part of the hip [18].

The lumbosacral corset limits several movements in the frontal plane. It is less rigid at the pelvis, allowing movements in both the sagittal and transverse planes. Moreover, the corset applies pressure on the abdomen; therefore, the intraabdominal pressure increases, which reduces stress on the spine and load on the spinal disc and extensors. Furthermore, it enhances the user's perception of proprioception. The lumbosacral corset can be used in cases of disc herniation, spinal stenosis, chronic back pain, pelvic fracture, and sprain of the lumbosacral spine [23-27].

Kim [28] investigated 69 patients who used the lumbosacral corset to treat a herniated disc or sprain in the lumbar spine region. Physical examinations (e.g., straight leg raising [SLR] and gait analysis) were performed, and the intensity of pain and clinical outcomes of using the lumbosacral corset were determined based on the criteria suggested by Stauffer and Coventry [29]. While the results of both SLR and gait analysis were "poor" in $63.77 \%$ and $59.4 \%$ of the patients, respectively, prior to use of the lumbosacral corset, improvements were noticed following its use (i.e., $84.06 \%$ and $85.50 \%$ of the patients reported a greater than "fair" result). These findings suggest that the use of the lumbosacral corset is effective in reducing pain and improving the activities of daily living. In 2001, Prateepavanich et al. [30] measured the claudication distance and pain score (VAS) in 21 patients with lumbar spinal stenosis without wearing a lumbosacral corset, and a week later with a lumbosacral corset, evaluated again and compared the results. As a result, a significant difference between the two groups, an average claudication distance was $393.2 \mathrm{~m}$ when wearing a lumbosacral corset and $314.6 \mathrm{~m}$ when not wearing a lumbosacral corset, and a mean value of pain score was 4.7 when wearing a corset and 5.9 when not wearing a lumbosacral corset. This result showed that the effects of lumbosacral corset in lumbar spinal stenosis.

\section{Thoracolumbosacral orthosis}

The thoracolumbosacral orthosis (TLSO) can be of the following two types based on the type of material used: soft and hard. In addition, it is classified based on the location and presence of structural elements as flexion adjustable, flexion/extension adjustable, flexion/extension/lateral flexion adjustable, and flexion/extension/lateral flexion/rotation adjustable. It is fabricated on the principle of three-point pressure. TLSO can be used to treat chronic back pain, sprains and fractures of the thoracic or lumbar spine, and spinal deformities, and for postsurgical management of the spine $[26,31]$.

TLSO is widely used in current clinical practice (Fig. 4). Owing to its light and breathable mesh fabric, it provides a comfortable fit. Furthermore, ergonomically designed plastic panels provide high stability through the application of abdominal pressure and insertion of the back panels. In addition, TLSO is adjustable through the connection of two elastic straps so as to fit the shape of the patient's body. It has a shoulder strap to prevent it from sliding out of place.

Jacobs et al. [32] assessed 15 patients with an osteoporotic vertebral compression fracture. Following the use of a semirigid TLSO for 6 weeks, their VAS scores and quality of life (measured using the Quality of Life Questionnaire of the European Foundation for Osteoporosis) were evaluated. The outcomes were decreased mean VAS scores (i.e., from 5 to 2 points) and improvements in pain (38\%), physical function (42\%), social function $(21 \%)$, and health perception (16\%). 


\section{Conclusion}

Several patients with spinal pain are encountered in clinical practice. Spinal orthoses are expected to alleviate pain and improve patients' lifestyle. Nevertheless, studies on the clinical efficacy of orthoses are neither quantitatively nor qualitatively sufficient to reach a solid conclusion. Therefore, additional investigations are required to issue guidelines on the appropriate use of spinal orthoses. Our study is limited in that we reviewed only most commonly used orthoses, accordingly more various orthoses should be reviewed in the future study.

\section{Acknowledgments}

\section{Conflicts of interest}

No potential conflict of interest relevant to this article was reported.

\section{Author contributions}

Conceptualization: YJC, MCC; Data curation: YJC, MCC; Formal analysis: MCC; Methodology: YJC, MCC; Investigation: YJC; Resources: YJC; Supervision: MCC; Visualization: YJC, MCC; Writing-original draft: YJC, MCC; Writing-review \& editing: YJC, MCC.

\section{Additional information}

The model provided written informed consent for the use and publication of his photographs.

\section{ORCID}

Yoo Jin Choo, https://orcid.org/0000-0002-3820-2279

Min Cheol Chang, https://orcid.org/0000-0002-7629-7213

\section{References}

1. Balague F, Mannion AF, Pellise F, Cedraschi C. Non-specific low back pain. Lancet 2012;379:482-91.

2. Salekzamani Y, Mirzaee S, Shakouri SK, Nezami N. Pain relieving effect of thermoplastic lumbosacral orthosis with adjustable posterior pad in chronic non-specific low back pain. Iran Red Crescent Med J 2011;13:903-5.

3. Jang SH, Chang MC. Follow-up of at least five years after lumbar transforaminal epidural steroid injection for radicular pain due to lumbar disc herniation. Ann Palliat Med 2020;9:116-8.

4. Do KH, Kim TH, Chang MC. Effects of interlaminar epidural steroid injection in patients with moderate to severe lumbar central spinal stenosis. Ann Palliat Med 2020;9:163-8.
5. Yang JY. The pathogenesis and medical treatment of spondylogenic pain. Asian Spine J 2010;4:57-63.

6. Lurie J, Tomkins-Lane C. Management of lumbar spinal stenosis. BMJ 2016;352:h6234.

7. van Tulder MW, Koes BW, Bouter LM. Conservative treatment of acute and chronic nonspecific low back pain. A systematic review of randomized controlled trials of the most common interventions. Spine (Phila Pa 1976) 1997;22:2128-56.

8. van Tulder MW, Koes B, Malmivaara A. Outcome of non-invasive treatment modalities on back pain: an evidence-based review. Eur Spine J 2006;15(Suppl 1):S64-81.

9. Azadinia F, Ebrahimi Takamjani E, Kamyab M, Parnianpour M, Cholewicki J, Maroufi N. Can lumbosacral orthoses cause trunk muscle weakness? A systematic review of literature. Spine J 2017;17:589-602.

10. Bible JE, Biswas D, Whang PG, Simpson AK, Rechtine GR, Grauer JN. Postoperative bracing after spine surgery for degenerative conditions: a questionnaire study. Spine J 2009;9:30916.

11. Muzin S, Isaac Z, Walker J, Abd OE, Baima J. When should a cervical collar be used to treat neck pain? Curr Rev Musculoskelet Med 2008;1:114-9.

12. Barati K, Arazpour M, Vameghi R, Abdoli A, Farmani F. The effect of soft and rigid cervical collars on head and neck immobilization in healthy subjects. Asian Spine J 2017;11:390-5.

13. Richter D, Latta LL, Milne EL, Varkarakis GM, Biedermann L, Ekkernkamp A, et al. The stabilizing effects of different orthoses in the intact and unstable upper cervical spine: a cadaver study.J Trauma 2001;50:848-54.

14. Beavis A. Cervical orthoses. Prosthet Orthot Int 1989;13:6-13.

15. Mealy K, Brennan H, Fenelon GC. Early mobilization of acute whiplash injuries. Br Med J (Clin Res Ed) 1986;292:656-7.

16. Rosenfeld M, Gunnarsson R, Borenstein P. Early intervention in whiplash-associated disorders: a comparison of two treatment protocols. Spine (Phila Pa 1976) 2000;25:1782-7.

17. Ghorbani F, Kamyab M, Azadinia F, Hajiaghaei B. Open-design collar vs. conventional Philadelphia collar regarding user satisfaction and cervical range of motion in asymptomatic adults. Am J Phys Med Rehabil 2016;95:291-9.

18. Kim JH, Park YS, Song JC, Shin HS, Chang YC. Prosthetics \& orthotics. 3rd ed. Seoul (KR): Topmed; 2006.

19. Kaufman WA, Lunsford BR, Lunsford TR, Lance LL. Comparison of three prefabricated cervical collars. Orthot Prosthet 1985;39:21-8.

20. Sparke A, Voss S, Benger J. The measurement of tissue interface pressures and changes in jugular venous parameters associated with cervical immobilization devices: a systematic review. 
Scand J Trauma Resusc Emerg Med 2013;21:81.

21. Motiei-Langroudi R, Sadeghian H. C2 body fracture: report of cases managed conservatively by Philadelphia collar. Asian Spine J 2016;10:920-4.

22. Morrisette DC, Cholewicki J, Logan S, Seif G, McGowan S. A randomized clinical trial comparing extensible and inextensible lumbosacral orthoses and standard care alone in the management of lower back pain. Spine (Phila Pa 1976) 2014;39:173342.

23. Rizzone K, Gregory A. Using casts, splints, and braces in the emergency department. Clin Pediatr Emerg Med 2013; 14:340-8.

24. Sullivan MS, Mayhew TP. The effect of lumbar support belts on isometric force production during a simulated lift. J Occup Rehabil 1995;5:131-43.

25. Terai T, Yamada H, Asano K, Nawata A, Iwasaki T, Henmi T, et al. Effectiveness of three types of lumbar orthosis for restricting extension motion. Eur J Orthop Surg Traumatol 2014;24(Suppl 1):S239-43.

26. Agabegi SS, Asghar FA, Herkowitz HN. Spinal orthoses. J Am Acad Orthop Surg 2010;18:657-67.

27. Schroeder S, Rossler H, Ziehe P, Higuchi F. Bracing and sup- porting of the lumbar spine. Prosthet Orthot Int 1982;6:13946.

28. Kim MH. A biomechanical effectiveness of corset and back brace for low back pain syndrom. Phys Ther Korea 1996;3:5966.

29. Stauffer RN, Coventry MB. Anterior interbody lumbar spine fusion: analysis of Mayo Clinic series. J Bone Joint Surg Am 1972;54:756-68.

30. Prateepavanich P, Thanapipatsiri S, Santisatisakul P, Somshevita $\mathrm{P}$, Charoensak T. The effectiveness of lumbosacral corset in symptomatic degenerative lumbar spinal stenosis. J Med Assoc Thai 2001;84:572-6.

31. Vander Kooi D, Abad G, Basford JR, Maus TP, Yaszemski MJ, Kaufman KR. Lumbar spine stabilization with a thoracolumbosacral orthosis: evaluation with video fluoroscopy. Spine (Phila Pa 1976) 2004;29:100-4.

32. Jacobs E, Senden R, McCrum C, van Rhijn LW, Meijer K, Willems PC. Effect of a semirigid thoracolumbar orthosis on gait and sagittal alignment in patients with an osteoporotic vertebral compression fracture. Clin Interv Aging 2019;14:671-80. 